\title{
AC 2011-165: ALTERNATIVE APPROACH TO ASSESSING MILITARY TRAINING FOR ADVANCED PLACEMENT INTO ENGINEERING AND TECHNOLOGY PROGRAMS
}

\author{
Kevin James Wainwright, BC Institute of Technology
}

Kevin Wainwright a faculty member in the School of Business at the British Columbia Institute of Technology in Vancouver, B.C., Canada. BCIT has over 50,000 full and part time students and is the second largest post-secondary institute in the province of British Columbia Kevin has his Ph.D. in economics from Simon Fraser University where his fields of specialization were mathematical economics, industrial organization, law and economics, and environmental economics. He is co-author of the book, Fundamental Methods in Mathematical Economics, the most widely adopted text in North American universities in the field of mathematical economics. Kevin is the BCIT Program Head for the Bachelor of Business Administration program and the director of the SITE Centre of Excellence, the research branch of the BCIT School of Business. He is the faculty sponsor for both the Reservist Re-Entry Program and SIFE BCIT From 2000 to 2005 he served as president of the BCIT Faculty and Staff Association. In May of 2010 Kevin was appointed to the Board of Governors for BCIT Kevin's professional and academic focus has been in Environmental Economics and the Economics of Education. Recent work includes: the economic impact of BCIT on the provincial economy, an analysis of intellectual property policies in Canadian universities and colleges, and forecasting models predicting student success in business schools, and a study of the impact of carbon taxes on regional airports and airlines. He has extensive teaching experience at BCIT and at other universities and colleges. Kevin has taught at the diploma level within the Institute's business, broadcast and engineering programs, and at the bachelor's degree level both at BCIT and at Simon Fraser University. At SFU Kevin supervises both master's and PhD thesis students, and taught economic theory and policy in the Masters of Public Policy program.

\section{Barbara Ellen Endicott-Popovsky, University of Washington - Information School}

Barbara Endicott-Popovsky, Ph.D., is the Director for the Center of Information Assurance and Cybersecurity at the University of Washington, designated by the NSA as a Center for Academic Excellence in Information Assurance Education and Research. She holds a joint faculty appointment with the Information School and Masters in Strategic Planning for Critical Infrastructure, following a 20-year industry career marked by executive and consulting positions in IT architecture and project management.

Her research interests include enterprise-wide information systems security and compliance management, forensic-ready networks, the science of digital forensics and secure coding practices. Barbara earned her Ph.D. in Computer Science/Computer Security from the University of Idaho (2007), and holds a Masters of Science in Information Systems Engineering from Seattle Pacific University (1987), a Masters in Business Administration from the University of Washington (1985) and a Bachelor of Arts from the University of Pittsburgh.

\section{Sarah A Rajala, Mississippi State University}

Sarah A. Rajala is Dean of the Bagley College of Engineering and Professor of Electrical and Computer Engineering at Mississippi State University. She earned the bachelor's degree from Michigan Technological University and the M.S. and Ph.D. degrees from Rice University. She has held professional appointments at North Carolina State University and Purdue University.

Dr. Rajala's research and teaching activities are in image and signal processing and engineering educational assessment. She has published numerous technical papers and books in these areas ( $>120)$. Dr. Rajala is a Fellow of the AAAS, ASEE, and IEEE and has received the Presidential Award for Excellence in Science, Mathematics, and Engineering Mentoring. She has an extensive record of leadership to professional organizations including serving as president of the ASEE, member of the Executive Committee of IFEES, as program evaluator and member of the executive committee of the Engineering Accreditation Commission (EAC) of ABET, and a member of the Board of Governors of the IEEE Signal Processing Society.. 


\title{
The Honour House Project: Reservist Re-Entry Program
}

\begin{abstract}
Both the United States and Canada invest a great deal of resources in the training of their military personal. Many of the skills and experiences accumulated by soldiers are those that are highly valued by civilian employers. Further, these skills are often embodied in academic programs, suggesting soldiers would have a comparative advantage in such programs; however, despite the efforts of government agencies, many soldiers are unable to convert their skills and training into meaningful careers. While there are several reasons why individuals leaving military duty have trouble re-integrating into work and education, one of the major obstacles is the difference between the military and civilian models of training and education. The differences create challenges to offering advanced placement or transfer credits for military training in civilian post-secondary institutions.

This paper presents the findings from a pilot program at the British Columbia Institute of Technology (BCIT), Vancouver, Canada. The program uses an alternative approach to assessing military training for advanced placement into technology programs. Instead of the traditional course-by-course credit assessment, the program uses an integrated model that gives block credit or "credential equivalence". This block credit is then used for advanced placement. Depending on the structure and field of the program being sought, the reservist receives significantly higher placement than would occur under most traditional models. The model is under review in the United States for application to GI Bill applicants transitioning from military service.
\end{abstract}

\section{Introduction}

The BCIT Honour House Project (Reservist Re-entry Program) ${ }^{1,2}$ is a pilot project that evaluates and quantifies the training and field experience of military and first responder personnel, creating civilian equivalents. Further, the program maps the potential pathways into a civilian career and assists Reservists in pursuing career goals.

The distinguishing feature of the program is its approach to assigning credits and equivalencies. As with most post-secondary institutes in Canada, BCIT does grant transfer credits to individual courses and modules delivered during military training; however, the program also grants block credit recognition or “credential equivalency." For the purposes of meeting the entrance requirements of a range of advanced diploma and degree programs, military training and experience is recognized as a technical diploma. This paper presents an overview of the BCIT model as well as its findings from initial placement of reservists.

The concept of Honour House is to be a home away from home for soldiers (and their families) when sent to Vancouver for medical treatment. Besides being a hospice, Honour House serves as an umbrella organization that links a variety of support services available to Reservists and First Responders. One of the key support services is career development which is provided to the Reservists by the British Columbia Institute of Technology (BCIT). 
Reservists often have difficulty finding a civilian job upon completion of their military service. Several reasons may account for this: minimal outplacement assistance being provided to Reservists; limited prior work experience outside of active service; and lack of awareness of career options. This is further exacerbated by any one of the many combat related health issues that can plague returning soldiers.

A pilot project was initiated by BCIT in early 2009, with its initial objective to provide Reservists with assistance in identifying their knowledge, skills and abilities, and potentially suitable career paths. The original project goal was to assist Reservists in re-entering the workforce; however, it quickly became apparent that there was an opportunity to offer them more alternatives than simply finding an entry level job.

In assessing the entire military training program from the perspective of re-entering civilian life, we recognized that many aspects of the military program aligned well with technical programs being offered by Canadian post-secondary institutions. Further, military personal acquired a range of skills valued by the private sector that would not necessarily show up in an individual's military file; however, these skills could be assessed and quantified in a systematic manner.

Because of the culture inherent to the military, the success of the program requires "buy-in" at the grass roots level. In order to gain acceptance by the Reservists, the philosophy and structure of the program was one of inclusion. The starting point was to identify the interests and needs of the Reservists. The program then would identify the skills and knowledge that a Reservist possessed, as well as any additional training necessary to achieve the desired career goal.

Based on Reservists' interests and skills, program participants tend to fall into one of three broad categories. Those who:

a) Wish to pursue or complete post-secondary education.

b) Would like to start a business.

c) Wish to obtain immediate employment.

The organization of this paper is as follows: The next section gives a brief overview of the Canadian Forces training modules that are relevant to this project. Section three describes the basic program structure at BCIT. Section four explains the reservist re-entry program at BCIT and section five gives a summary of results and initial findings.

\section{Canadian Forces Military Training Modules $^{3}$}

The following is a brief overview of the reservists' formal military training covered in our analysis: 


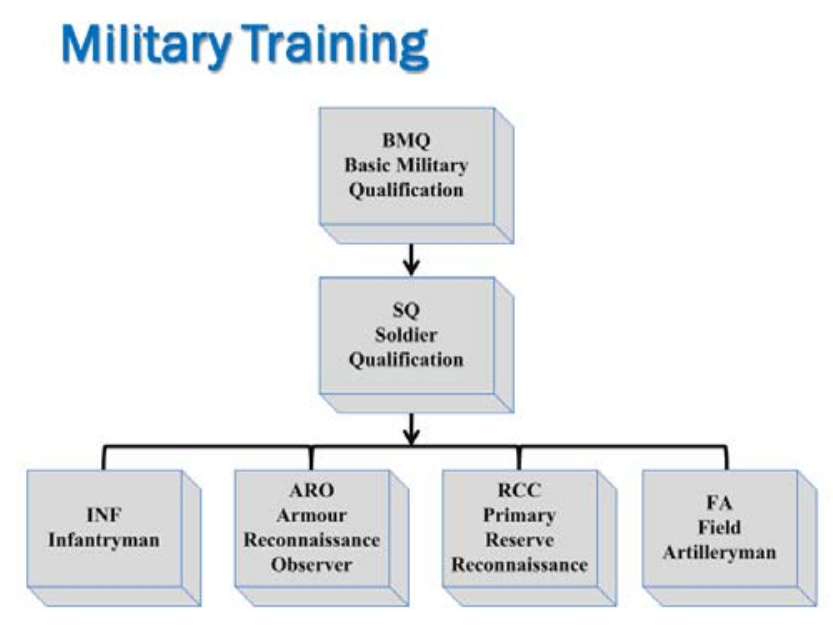

Figure 1: Overview of Canadian Forces Training Program

All reservists in the Canadian Forces will have the following two training modules:

\section{[1] Primary Reserve Basic Military Qualification (BMQ)}

The aim of the training resulting from this Training Plan (TP) is to provide the reserve soldier with the basic Canadian Forces common core skills and knowledge. These common skills and knowledge provide the foundation on which the reserve soldier's future training within Army NCM DP 1 will be based.

\section{[2] Soldier Qualification (SQ)}

The aim of the training resulting from this Training Plan (TP) is to prepare soldiers for employment within the Army. Army Developmental Period One (DP 1) is composed of an Army Land Environmental Training package, designed to provide the candidate with the theoretical knowledge, practical experience, individual skills and the confidence required to participate at the section level, in a platoon context, in an operational environment.

In addition to the two modules above, reservists will have at least one of the following four modules prior to being deployed.

\section{[3A] Infantryman (INF)}

The aim of the training resulting from this Training Plan (TP) is to produce an Infantryman capable of performing the duties required as a member of a rifle section in the context of a rifle platoon in operations.

\section{[3B] Armour Reconnaissance Observer (ARO)}

The aim of the training resulting from this Training Plan (TP) is to produce a Crewman capable of performing their duties as a Recce Observer within an Armour Recce Regiment. 
[3C] Primary Reserve Reconnaissance (RCC)

The aim of the training resulting from this Training Plan (TP) is to produce a Crewman capable of performing their duties in an Armour Reserve Reconnaissance Regiment.

\section{[3D] Field Artilleryman (FA)}

The aim of the training resulting from this Training Plan (TP) is to produce Artilleryman capable of performing all gun detachment duties except those of the Detachment.

Both reservists and regular forces personnel go through these training modules. While there are clearly a great deal more training modules in the armed forces, the above list is representative of the basic training received by all service personnel who are deployed.

\section{The British Columbia Institute of Technology (BCIT)}

BCIT is one of British Columbia's largest post-secondary institutions with more than 48,000 students enrolled annually (16,600 full-time, 31,600 part-time). BCIT’s primary focus is in applied education, offering certificates, diploma and degrees, as well as apprenticeships and industry training. The fields of instruction and research at BCIT are in business, computing, engineering, health sciences, natural sciences and trades.

The BCIT program ${ }^{4}$ structure offers a variety of educational pathways through a laddering process. In most programs students will complete an intensive two-year diploma in a field of study. Students may then ladder into a degree program with the diploma being the foundation. Degrees are 60 credits of advanced study beyond the diploma of the same field.

In addition, students can change disciplines between the diploma and the degree by completing a post-diploma or advanced diploma. Post-diplomas are typically nine months of full time study that required a diploma from a different field as the entrance requirement. For example, a civil engineering diploma student may choose to take a post-diploma in human resource management. This, in turn, will allow the student to enter the business administration degree program (60 additional credits)

\section{BCIT Program Structure}

\section{Full Time Diplomas 2 years - 120 credits}

- Health Sciences (X-Ray, Nuclear, Biotech)

- Engineering (Civil, Electrical, Mechanical, GIS)

- Computer Science

- Business (Marketing, HR, Finance, Accounting, Operations)

\section{Degree Programs - 60 credits above diploma}

- Bachelor of Business Administration

- Bachelor of Science (Engineering)

- Bachelor of Technology (Accounting, Computing, Construction, Engineering, Environmental Sciences)

- Bachelor of Nursing

The post-diploma programs are also popular pathways for individuals who have credentials from other institutes, especially for those with degrees other than business or engineering. Diplomas 
and post-diplomas in the same subject area are viewed as equivalent from the perspective of external accreditations and admissions to advanced programs.

For most disciplines at BCIT, the diploma program and post-diploma program ladder into a degree completion program.

\section{Reserve Re-entry Program at BCIT}

This section gives an overview of the Reservist Re-entry program and the approaches used in assigning credits and awarding advanced placement into BCIT programs. Besides assessing and placing individual reservists, the project also involved the construction of a comprehensive database of military training cross-referenced to BCIT courses and programs.

The data was derived from two sources. First, the Canadian Forces provided all documentation associated with the modules described in the previous sections. This data was loaded into a database that contained all BCIT course and program materials and learning outcomes. A custom search engine, developed for this project, was used to construct a series of mappings from military modules into BCIT courses.

Second, a series of one-on-one and group interviews were conducted with potential candidates from the Canadian Forces. The interview process served two purposes: first, it allowed us to validate the cross-referencing carried out in the database construction. Second, the interview process allowed us to identify additional skills and learning outcomes that were not part of the formal military training modules. Almost all participants in the program had been deployed for at least seven months in Afghanistan or a peace-keeping mission elsewhere in the world. During deployment, reservists would acquire a variety of skills and experience in such areas as leadership, time management, logistics and conflict resolution.

A summary from the one-on-one interviews, combined with the military training transcripts, would be added to the individual's academic history. The content of the individual's file would be assessed in two ways. First, individual transfer credits would be identified and a summary of transfer credits and the associated programs would be produced. This would allow the reservist to see in which areas he/she had credits and how much additional education would be needed to achieve any given credential.

Second, the individual's entire history would be "bundled" and evaluated as a credential equivalent. A threshold level of formal training and field experience was identified and deemed to meet the educational equivalent of a "technical diploma". From this determination a mapping of advanced programs (post-diploma) which require a diploma as part of the admission was produced. The assessment from this method would be added to the individual's application file.

The illustrations below will refer primarily to business programs; however, the basic model is consistent across all disciplines at BCIT. The reasons for using business programs are twofold: first, their diversity and flexibility made them relatively easy to map. Second, business programs were identified as one of the most popular choices amongst reservists. Since certain business 
programs are offered as both two-year diplomas and one-year post-diplomas, they serve well as a baseline for comparing the two different approaches to advanced placement.

\section{Course-by-Course Credit Model}

The first option is the individual mapping of transfer credits on a course-by-course basis. In this scenario the reservist's training would be formally recognized and the reservist would be exempt from specific courses upon entering any program at BCIT. The military qualification will be recognized as any other previous institutional qualification is recognized upon applying. Any individual who comes to BCIT with any history of training can present their prior course information which can be transferred and applied to comparable courses at BCIT. The following diagram demonstrates the first option, which is course-by-course credit classification:

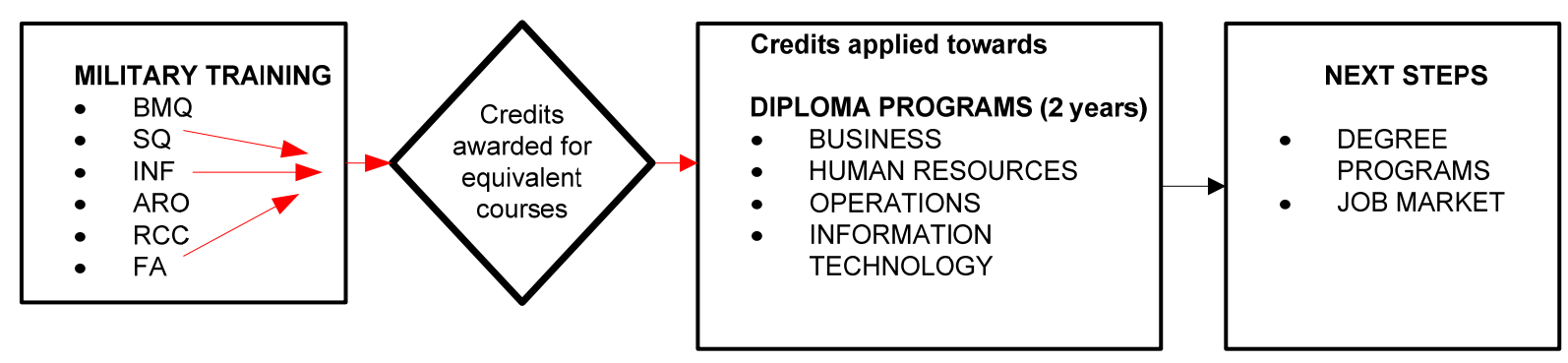

Figure 2: Course-by-Course Progression from Military to BCIT Diploma Programs

The diagram below illustrates a specific example from the analysis of the BMQ training module. The BMQ training contains skill sets such as communication, organizational behaviour, human resource management, and so on, and they then are matched up according to specific courses within the Human Resource Management program (HRMG) and the Business Management program (BMGT). The diagram below demonstrates examples of two separate programs towards which the reservists would receive course credits.

\section{Credential Equivalency Model}

The second option is based on block credits, instead of individual course mapping. In this scenario, the reservist would have undergone a number of military training modules which could be classified as a block credit for the purpose of meeting the Post Diploma (PD) program admission requirements. The PD program takes individuals who have a prior credential, such as a degree/diploma in any non-business field (i.e. biology, psychology, political sciences).

The reservist's entire list of skills generated from their informal and formal training can be grouped together and potentially treated as a diploma. This would enable a reservist to go straight from the military into one of these programs. 


\section{Basic Military Qualification (BMQ)}

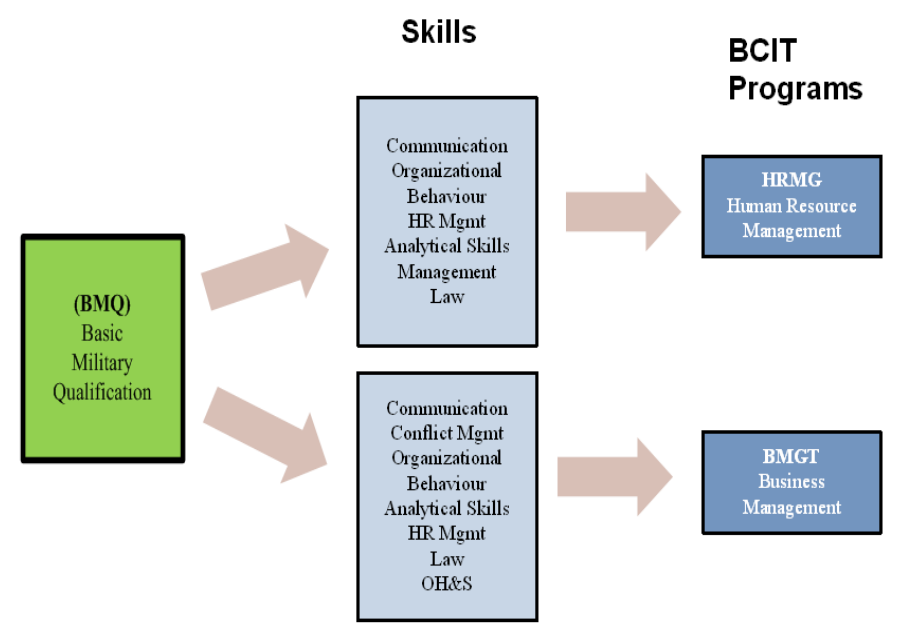

Figure 3: Basic Military Qualification Learning Outcomes to BCIT Programs

The following diagram demonstrates the second option, which is block credit classification:

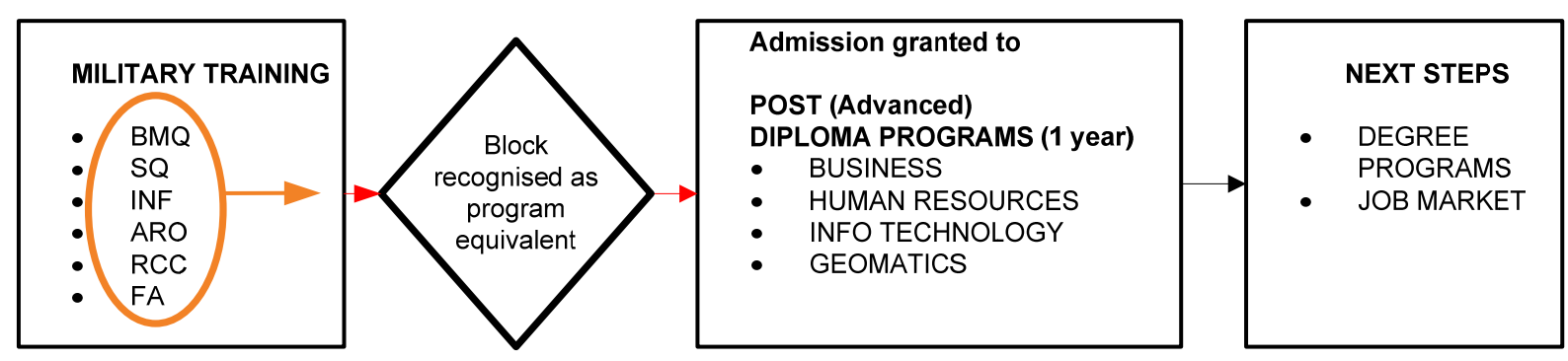

Figure 4: Block Credit Admission from Military to Post Diploma

\section{Initial Results and Findings}

As of the 2010/2011 academic year approximately 40 reservists are participating in the program either on a full-time or part-time basis. Of theses, nine of the reservists are part of an entrepreneurial workshop that is assisting in the development of business plans and the launch of individual businesses. A partnership with a local bank allows the reservists to access start-up capital to launch their ventures. The rest are pursuing educational paths in business, health and engineering. 
Four of the initial group of reservists who entered the program are about to complete the Business Management Post-Diploma program and have been accepted into the business degree program for fall 2011. They are expected to complete their degrees in summer 2012.

The initial phase of the pilot project revealed some interesting results. First, there was no clear indication that reservists would choose programs that were closely aligned to their military training. For example, the interest in health sciences was disproportionate to the amount of training and experience reservists' possessed compared to other technical fields.

When discussing their future civilian career goals the participant's outlook and attitude can generally be described as one of three types:

1. Unsure of what they wanted to do and were looking to the program for guidance and direction,

2. Knew where they wanted to go, were taking steps towards that goal, and wanted assistance if it was available, or

3. Had an idea in mind but were unsure of how to accomplish that goal.

Second, the skill sets of reservists tend to be greater than is conveyed from their military transcripts. Further, the reservists themselves were either not aware of all their skills or could not articulate them until probed during the interview process. Two issues worth noting are (i) the "we" versus "me" mindset in conveying information, and (ii) the inconsistencies in documented, versus actual, job descriptions and duties:

"We" versus "me" statements

Teamwork is a very important and necessary part of the military culture. Individuals who join the military are taught how not only to work in teams and lead teams, but also how to change one's mindset from "me" to "we". This mindset, while extremely important in the success of military operations, makes it difficult for members of the military to emphasize the particular roles, skills and experiences which are unique to them.

\section{On the Job Learning}

One of the most common statements interviewers would hear from participants when asked the question about their official role in Afghanistan, or a similar deployment / special operation, was that while the participant was officially in " $X$ ” role they were really a "Y" or a "Z". Many participants when answering the aforementioned question talked about how when they arrived at their place of deployment, something would happen that required them to assume a completely different role from what they were officially trained in work-up training.

The two issues cited re-enforce the importance of combining individual assessments with the establishment of systematic credit and advanced placement programs. This is particularly important for the "credential equivalent" model of block credit recognition.

Given the promising results of the pilot project, the next step is to assess the robustness of the program and its transferability to other institutes and jurisdictions. Toward this end, BCIT is partnering with the University Washington and Mississippi State University to study ways to implement similar models. 
While almost all post-secondary institutions award transfer credits and advanced placement, this tends to be limited to the course-by-course model. The block credit model being used for reservists at BCIT is unique in Canada and most other countries; however, for Canadian reservists, it is the preferred model. The block approach offers flexibility to the placement of reservists that the traditional path lacks. For those who qualify, it offers a path to a degree that has a much shorter time frame than the alternatives.

\section{Bibliography}

[1] Aniks,Tatiana \& Condrashoff, Natalie, "Reserve Re-Entry Program” Final Report. BCIT School of Business May 2009

[2] Mullen, Teresa \& Rogers, Rebecca, “Honour House: Reserve Re-Entry Program Year 2” Final Report. BCIT School of Business, May 2010

[3] Government of Canada:

- $\quad$ ARMY DP 1 - INFANTRYMAN Training Plan A-P9-031-DP1/PH-B01 November 2007 Source:

Canadian Forces, Seaforth Highlanders, Regimental Headquarters: Seaforth Armoury 1650 Burrard Street Vancouver, BC V6j 3G4

- $\quad$ ARMY NCM DP 1 BASIC MILITARY QUALIFICATION A-PD-050-BMQ/PH-H16 November 2007 Source: Canadian Forces, Seaforth Highlanders, Regimental Headquarters: Seaforth Armoury 1650 Burrard Street Vancouver, BC V6j 3G4

- $\quad$ ARMY NCM DP 1 - SOLDIER QUALIFICATION A-P2-002-D10/PH-B01 September 2004 Source: Canadian Forces, Seaforth Highlanders, Regimental Headquarters: Seaforth Armoury 1650 Burrard Street Vancouver, BC V6j 3G4

- $\quad$ DP 2 ARMOUR RECONNAISSANCE OBSERVER A-P2-011-S01/PH-B01 May 2005 Source: Canadian Forces, Seaforth Highlanders, Regimental Headquarters: Seaforth Armoury 1650 Burrard Street Vancouver, BC V6j 3G4

- $\quad$ MOC NCM DP2 INFANTRY PLATOON SUPPORT WEAPONS A-P9-031-DP2/PH-B01 November 2005 Source: Canadian Forces, Seaforth Highlanders, Regimental Headquarters: Seaforth Armoury 1650 Burrard Street Vancouver, BC V6j 3G4

- TACTICAL COMBAT CASUALTY CARE April 2006 Source: Canadian Forces, Seaforth Highlanders, Regimental Headquarters: Seaforth Armoury 1650 Burrard Street Vancouver, BC V6j 3G4

- ORGANIZATIONAL, SOCIAL AND DEMOGRAPHIC CHANGE IN THE CANADIAN FORCES Source: http://www.internationalmta.org/1998/9837.html

- Statistics Canada July 2008 Perspectives - A Profile on Canadian Forces by Jungwee Park Source: http://www.statcan.gc.ca/pub/75-001-x/2008107/pdf/10657-eng.pdf

- Canadian forces deployed outside of Canada 1992-2003 Government of Canada Source: http://www.army.forces.gc.ca/land-terre/life-vie/army-armee/statistics-statistiques-eng.asp Date Modified: 2009-07-27

- $\quad$ Fit to Serve: Universality of Service and Related Support Programs June 29, 2010 Source: http://www.forces.gc.ca/site/news-nouvelles/news-nouvelles-eng.asp?cat=03\&id=3449

[4] BCIT Policy 5003: Admissions and Prior Learning Assessment and Review. March 11, 2009 http://www.bcit.ca/files/pdf/policies/5003_pr1.pdf 